\title{
STUDENTS' PERCEPTION ON LEARNING TECHNICAL VOCABULARIES THROUGH VOCABULARY SELF-COLLECTION STRATEGY
}

\author{
${ }^{1}$ Difa Viola, ${ }^{1}$ Elih Sutisna Yanto, \& ${ }^{\mathbf{1}}$ Mobit \\ ${ }^{1}$ English Language Department, Universitas Singaperbangsa Karawang, Indonesia \\ Corresponding Author Email: diva.viola98@gmail.com
}

\begin{tabular}{|c|c|}
\hline Article Info & Abstract \\
\hline $\begin{array}{l}\text { Article History } \\
\text { Received: August } 2020 \\
\text { Revised: September } 2020 \\
\text { Published: October } 2020\end{array}$ & $\begin{array}{l}\text { The objective of this research was to investigate vocational students' perception } \\
\text { on learning technical vocabularies through Vocabulary Self-Collection Strategy. } \\
\text { This research provides two research questions, In what ways Vocabulary Self- } \\
\text { Collection Strategy facilitates students in learning technical vocabulary? What }\end{array}$ \\
\hline $\begin{array}{l}\text { Keywords } \\
\text { Vocabulary self-collection } \\
\text { strategy; } \\
\text { Technical vocabulary; } \\
\text { Students' perception; }\end{array}$ & $\begin{array}{l}\text { are the constraints of the students in the learning of technical vocabulary using } \\
\text { Vocabulary Self-Collection Strategy? This research was using qualitative } \\
\text { methodology and virtual classroom action research as a research design due to } \\
\text { the pandemic of Covid-19. The participants of this research are grade 10th } \\
\text { students of audio-video engineering from one of vocational high school in } \\
\text { Karawang, West Java, Indonesia. A chosen audio-video engineering journal was } \\
\text { distributed in order for the students to explored and selected new important } \\
\text { words and added the information they got from it to the vocabulary self- } \\
\text { collection strategy (VSS) chart. And also, semi-structured interviews have been } \\
\text { completed to know their perception on vocabulary self-collection strategy during } \\
\text { learning technical vocabulary using VSS (selecting and nominating new words). } \\
\text { The result of this study showed that the vocabulary self-collection strategy had } \\
\text { positive impacts on students' vocabulary size, their ability to comprehend text, } \\
\text { and the constraints that the students had during the VSS process. }\end{array}$ \\
\hline
\end{tabular}

How to cite: Viola, D., Yanto, E.S., \& Mobit. (2020). Students' perception on learning technical vocabularies through vocabulary self-collection strategy. JOLLT Journal of Languages and Language Teaching. 8(4), 391401, DOI: https://doi.org/10.33394/jollt.v\%vi\%i.2802

\section{INTRODUCTION}

Secondary school teachers reported that their students had no specialized or disciplinary vocabulary; as a result, they found it difficult to understand disciplinary textbooks and manuals in English (Widodo, 2015). Regarding preliminary research within the observation during teaching practicum in November-December of 2019, the researcher found that most students are hard and difficult to understand the lesson that is being delivered in the classroom. Vocational students still ignored the importance of English vocabulary size to their future careers. According to Keliat, Virgianita, Banna, \& Aryanto (2013), while Indonesia was the largest labor contributor to ASEAN, the level of English competence of Indonesian labor is still below the expected standard. A study conducted by Education First (Valentina, J 2017) clarified that Indonesia was ranked 39th out of 80 countries with 52.15 scores of English skills, and this has an impact on the hiring process. This research describes a review of students' perception of learning technical vocabularies using vocabulary self-collection strategy (VSS) and students' perceptions of the use of technical journals for understanding disciplinary vocabulary in content-based EFL instruction.

VSS is one of the approaches that facilitate the use of context throughout vocabulary selection (Haggard, 1982). VSS is mainly used for format development in academic disciplines and is characterized as a "collaborative framework that offers practice in defining 
key terms or words and using meaning to determine context" (Manzo, Manzo \& Thomas, 2005, pp. 174-175). VSS has also been introduced to encourage students to create a list of selected words from the post-reading content to analyze and understand the selected words. It is used to encourage them to extend their prior knowledge of the chosen words or terms, deepen their comprehension of them, and inspire them to improve their knowledge of the words.

The approach not only introduces student word skills but also creates solutions to unlock keywords or terms in a text that will allow them to open up to content information. It contains the following steps: the selection of words, interpretation of chosen words, and finalization of the word list and extension of the knowledge of words (Wulansari, 2016). Martin (2002: 89-90) categorizes VSS in the following steps: Teachers introducing the purpose of VSS to students. Teachers demonstrate how important words can be selected and nominated from readings. Teachers will demonstrate how to use context and other resources to learn the meaning of words. Teachers write the word, the context in which the selected word used, the meaning of the selected word, and the reason for choosing the words on the vss chart paper. Teachers engage students in the vocabulary self-collection process. After students familiar with the strategy, teachers guide how to encourage the use of VSS during reading. Students in the small groups discuss the words that they want to dominate. And then the students write the words to the chart.

The development of vocabulary is essential for the effective use of second languages and takes a significant part in the development of comprehensive spoken and written texts (Laufer \& Nation, 1999), (Maximo, 2000), (Read, 2000), (Gu, 2003), (Marion, 2008), and (Nation, 2011). Learning technical vocabulary is very beneficial to the students, particularly for second-language English students (Thornburry \& Nakata, 2004; 2008). Based on the employers' perspective, according to Adawiyah and Bambang (2003), English is very important in terms of supporting their technical skills in their work. The key requirement for engineers is English language proficiency, from the scale of their participation in the professional settings to reach the desired position in their career path and international project. English language skills also provide a tremendous benefit for those willing to work outside their own country (Arkoudis et al. 2014, Cole \& Tibby 2013, Knight \& Yorke 2004).

The VSS offers the advantages of a more efficient teaching and learning process. The main advantages are that students can develop their learning skills, find the best way to recognize words from their readings, strengthen their vocabulary, and be consistent (Martin, 2002:88). Other advantages include an improvement in the student vocabulary list that is suitable for pre-and post-reading, which helps students assess the meaning of reading (Meiningsih, 2004).

VSS's primary benefits are that the students can keep their way of study, find the best way to identify the words from their readings, improve their vocabulary and be a word conscious (Martin, 2002:88). Using this strategy, the students will have a new vocabulary list that can help them use English. During VSS, students use their rationale in selecting new words in understanding certain words that they have already found. Teaching VSS is facilitated to help students finding new words in a way they are learning. Thus, VSS is a suit and good strategy for learners in discovering the new meaning of the word that use within the classroom as well as they are encounter unfamiliar and important words on their own. The process of VSS would make students interested in learning vocabulary because they select the words that they should learn.

Therefore, the present study examines the following questions: In what ways Vocabulary Self-Collection Strategy facilitate students in learning technical vocabulary? What are the constraints of the students in the learning of technical vocabulary using Vocabulary Self-Collection Strategy? 


\section{RESEARCH METHOD}

Research materials was prepared by finding the source that was distributed to the students to learn English using VSS, that the selected words were put into VSS chart. To collect the data, the researcher conducted the following procedures: (1) The researcher created Google Classroom classes and WhatsApp group to interact with the students during collecting the data; (2) After all of the students were in the group, the researcher explained how the activities would be worked and done; (3) Scaffolding or Pre-Stage: the first step taken before starting research was to explain to students about VSS and its purpose in the process of learning in class. By gave them a stimulus so that they were interested and curious. To choose words that were suitable and important to them, in what context it was used, and how to find the meaning of the word. Then the teacher gave an example to later be followed by students from the Audio-Video Engineering journal that already contained text about engineering, the workplace, or around academia that students need to know. Throughout the process, the teacher demonstrated how to use the strategy; (4) During stage or Small Group Discussion: the teacher instructed students to form groups of 5 people in one group, then look for 5 words per person if they found it was difficult and important to know, discussed it and then filled in the charts according to their respective parts (choice of words, which part of the word, what it means according to them, what they mean in the dictionary, and the reason for choosing the word). In this process, it was encouraged the students to determine the meaning and every part of the vss chart as best as they can; (5) Post-stage or present: After the students have finished the discussion and got as many as 25 words in one group, all members in the group were presented and explained the findings of their words and put them in the VSS chart. If needed, the researcher added more important words that have not been included yet; (6) The students submitted Vocabulary Self-Collection Strategy chart and reflective journals to Google Classroom. After all the steps above were done, the researcher interviewed the students. The researcher applied a semi-structured interview to get the data.

\section{Research Design}

This research uses a qualitative methodology and the type of research design used in this research is Virtual Classroom Action Research. Virtual Classroom Action Research is online learning where participants can communicate, interact, and learn resources during the pandemic of Covid-19. Virtual learning environments can provide learners with opportunities for accessibility, engagement, and collaboration (Gedera, Williams \& Wright, 2013). This section contains author(s) 's sufficient detail of the preparation of the current study dealing with data collection and processing.

The researcher conducted some following steps to collect the data about responses of students to the use of vocabulary self-collection strategies (VSS), such as Vocabulary SelfCollection Strategy (VSS) chart of the students, reflective journals, and interviews. 1) VSS chart was used to see the students' process of selecting unfamiliar words and the reason why they chose it, in this part explained that the students have a lack of vocabulary. 2) Reflective journals of the students, reflective journals were obtained from students' diary about their experience during the English learning process of using VSS. VSS chart and reflective journal charts submitted to the Google Classroom by the students. 3) Semi-structured interview; interview was used to gained in-depth information on their vocabulary learning experience and vocabulary learning thoughts using VSS. The interview was done by interviewing the students via WhatsApp. Basically, this study is investigating the use of Vocabulary SelfCollection Strategy to learn technical English vocabulary in online platform based on audiovideo engineering students' perceptions. The platform that used is Google Classroom and Whatsapp. 


\section{Sample of the Current Study}

This study was conducted in one of the vocational high school located in Karawang, West Java, Indonesia. The participants of this study contain students who are in the 10th grade majoring in audio-video engineering. They come from the age range of 16 to 17 years old. The participants have an average of English skills; vocabulary. They spoke in three languages: Indonesian, Sundanese, and Javanese. They have difficulties learning English because of the lack of vocabulary and the lack of interest to learn English. language proficiency helps students to compete with others in either an academic field or a professional field.

\section{Instruments}

The researcher conducted some following steps to collect the data about responses of students to the use of vocabulary self-collection strategies (VSS), such as Vocabulary SelfCollection Strategy (VSS) chart of the students, reflective journals, and interviews. 1) VSS chart was used to see the students' process of selecting unfamiliar words and the reason why they chose it, in this part explained that the students have a lack of vocabulary. 2) Reflective journals of the students, reflective journals were obtained from students' diary about their experience during the English learning process of using VSS. VSS chart and reflective journal charts submitted to the Google Classroom by the students. 3) Semi-structured interview; interview was used to gained in-depth information on their vocabulary learning experience and vocabulary learning thoughts using VSS. The interview was done by interviewing the students via WhatsApp. Basically, this study is investigating the use of Vocabulary SelfCollection Strategy to learn technical English vocabulary in online platform based on audiovideo engineering students' perceptions.

\section{Data Analysis}

To analyze the data from the reflective journals and interviews, the researcher used some steps which deal with the procedures/steps in analyzing qualitative. In analyzed the data, the researcher used six phases of thematic analysis provided by Braun \& Clarke (2006).

The steps are explained as follows; (1) Familiarizing with the data: the researcher became familiar with the data (interviews and reflective journals) by reading and re-reading the data from students' reflective journals, assignments from Vocabulary Self-collection Strategy chart, and chat interview with the students; (2) Coding: this involved generating conceptual and systematic by removed or reduced unnecessary data from reflective journals of the students and interviews. The researcher was coded every data item and ended this phase by collated all their codes and relevant data extracts. The data were managed so that there were no data that are unclear and unimportant data were reduced; (3) Searching for themes: This 'searching' is an active process; themes were not hidden in the data waiting to be discovered by the researcher, rather the researcher constructs themes. The researcher was ended this phase by collated all the coded data relevant to each theme. From this step, the researcher found and divided three themes from all of the data (students' reflective journals and interviews) that have been collected; (4) Reviewing themes: The researcher reflected on whether the themes were relevant to each theme of data, and began to define the nature of each theme, and the relationship between the themes. All the data were reviewed to make sure when explaining it that the data were connected to each theme; (5) Defining and naming themes: it required the researcher to conduct and write a detailed analysis of each theme by identified the 'essence' of each theme and constructed a concise, punchy, and informative name for each theme. In this process, all of the data that has been constructed through themes were added names to each of the themes to define the themes. 
Writing up: Writing-up involved weaving together the analytic narrative and (vivid) data extracts to tell the reader a coherent and persuasive story about the data, and contextual it concerning existed literature. The data that already has been completed then they were reported and explained in detail and in-depth explanation, providing the shreds of evidence to support the report of the research.

\section{RESEARCH FINDINGS AND DISCUSSION Research Findings}

Three main themes were identified from students' reflective journals and interviews: (1) Vocabulary Self-collection Strategy helps students to comprehend text. (2) Vocabulary Selfcollection Strategy helps students to increase new vocabulary size and (3) Constraints of the students during the process of Vocabulary Self-collection Strategy.

\section{Vocabulary Self-collection Strategy helps students to comprehend text}

The students' responses and perceptions during the process of VSS were very positive when they studied the assignment they were gaining many advantages in using this strategy, one of them was in the way they comprehend the meaning of a text through the new words. This enables students to learn new vocabulary depending on individual experiences and world awareness (Martin, Martin, \& Ying, 2002, p. 34). This strategy was very useful, helpful, and valuable to be applied by the teachers for learning and teaching English to the students, especially with the specialized field. All of the students agreed and claimed the same argument which is good and it should be used more in learning English. This explanation from the students will be pointed out as student's Vignette 1 and 2.

\section{Student's Vignette 1}

VSS helped me in understanding new words that I had never learned in school and I have never seen in textbooks. The process of selecting new words and their meaning helped me and made me a little bit easier to comprehend a text and to be applied English in education, communication, or even in my specialization.

\section{Student's Vignette 2}

Through the process of selecting the words, the VSS helped me became familiar with the words. The words I found were important to know as an engineer and I'm sure it will be valuable for me and my classmates. This can be done in learning individually or in a group.

From the vignettes of the students, it indicates that Vocabulary Self-collection strategy is a suitable strategy that can be used by the teachers in teaching English as the students find some new words that they believe were important for them and for their classmates to know it. They also reported that during this process, they felt the positive impacts. Students were exposed to found new words by themselves that made them familiar with words and they could use it in any other areas that have the same context. This strategy could be work in individuals and in groups that made the students feel enjoy and interest more to learn English.

\section{Vocabulary Self-collection Strategy helps students increase new vocabulary}

Vocabulary Self-collection Strategy provided another advantage of learning English by using it. This strategy did not only help students to comprehend new vocabulary but also increased their vocabulary list as the students were familiar with the words that they already found in the previous meeting they were submitted to Google Classroom. Vocabulary Selfcollection Strategy made them independent and active in finding new important words and they will be familiar with the words that they have already found. This was such a good move for them to learn and master English skills when they applied in the workplace, education, or any other purposes. There are several cognitive processes involved in reading comprehension, good vocabulary skills are provided to facilitate learners to read competently (Taylor et al. 2009). The students' comments about this idea is presented in the following Vignette 3 and 4. 


\section{Student's Vignette 3}

When I was searching for the new words and its meaning, VSS made me remember or memorize the meaning of it as I searched it. This will make me familiar if I see and hear the words in a text or spoken. i.e: video auxiliary data, multicasting, video sequence, etc. I learned the words naturally when I did not know the words before.

\section{Student's Vignette 4}

Through VSS, I learned about the confidence for myself as I searched the words based on what I think it was important to know, and I gained a lot of new words that I did not know and I did not understand before. But as I searched for new words, I became aware of any words that I had just learned in sources like texts or spoken.

From these evidences, it showed that the Vocabulary Self-Collection Strategy provided the students with a good opportunity in students' learning outcomes that is increasing the vocabulary list of the students. The more often the activities are performed by searching or selecting for new words as many as possible, the more important words were gained to be used in different fields. And it also could be used to give students the opportunities to demonstrate their knowledge. Vocabulary Self-collection Strategy also could use their knowledge to maximize the progress of their vocabulary list.

\section{Constraints of the students during the process of learning technical vocabularies}

During the process of this strategy, most of the students have had constraints in searching the meaning of the words and lots of time-consuming in finding it. They had no idea what the words mean and that was the first time they saw the words because in school or English subject they were never learned about that vocabulary to them before as they explained in a reflective journal; when I was searching the words, I did not understand at all because I never taught about it in school and for that, I had a hard time in understanding the meaning. This is why students should learn from their more qualified peers and their teachers as a more professional person (Vygotsky's 1978, p. 86). This is the right time for them to learn new vocabulary that is related to their specialized field to use it for any purposes. The students mentioned this challenging activity explained below:

\section{Student's Vignette 5}

When I was selecting and nominating the words, I did not understand at all. So I had a difficult time finding the meaning because I'm not good at English and I can't understand the words but I tried to search the meaning in online and offline dictionaries.

Student's Vignette 6

Through the process of VSS, I found some words that were difficult for me also there were words that I did not understand. When I was searching for meaning, I did not understand it and I was confused when it was already translated into Indonesian. The words were new for me, I never saw it before so that's the reason why I was confused about it.

Student's Vignette 7

During searching and nominating new words was a very difficult thing for me, because I just knew the words when I study it and I've done it so confused in a way of how the words should be placed in using it and how to apply it when we will be using it in a different context. Fortunately, I used online dictionaries to translate it from English into Indonesian.

Student's Vignette 8

When I was learning specialized vocabulary through VSS, I felt the difficulty in finding the meaning of the words. It indeed allowed me to explore the words independently but I found a lot of words that I did not understand. For me, the words on the text were the new ones and a lot of words that I was never found in school textbooks before.

Student's Vignette 9

During the process of selecting the words, I did not understand all the words in the text that has been given. There were a lot of new words I just found that I never learned during teaching and learning in class or even in textbooks. Besides, I had a difficult time when I searched the meaning and I'm not good at English.

The constraints faced by the students based on the process of translating English words into Indonesian were when they read the text there were so many words they did not know it 
goes the same in searching for the meaning in the dictionary, many unrecognized words were found by students. The reason why there were so many unrecognized words for them was because of the lack of vocabulary list that they have. Due to so many unfamiliar words, the student found it difficult to read and understand the texts. And it also took lots of timeconsuming when the words that they have already translated into Indonesian are very confusing. They should make sure the right meaning of the words by searching or translating it in Google or asking their friends and their teacher.

According to Lerner (2000), learners with a rich knowledge of reading prefer to read more and enhancing their skills compared to those with bad reading experience. The more they read, the more they get used to the words.

\section{Discussion}

The discussion focused on the findings of the two proposed research questions. The discussion are: (1) In what ways Vocabulary Self-Collection Strategy facilitate students in learning technical vocabulary? (2) What are the constraints of the students in the learning of technical vocabulary using Vocabulary Self-Collection Strategy?

Ways that facilitate students in learning technical vocabulary through Vocabulary Selfcollection Strategy

Teaching words is a vital element of learning a language as languages are word-based (Thornbury, 2002). Learning English using Vocabulary Self-collection Strategy facilitates students in so many advantages that help students to comprehend new words that they have never learned before and helps students to get a new vocabulary list. Since the more frequently students searching for new words or reading texts that are important to them and the more they have learned a lot, the more vocabulary it makes their comprehension in reading that is relevant to their context increasingly, they will also become a good reader in understanding the meaning in detail. They have gotten benefit from learning words or making a connection for a better understanding of new words. Shiotsu and Weir (2007) reported that the level of linguistic comprehension of the learner plays a role in their understanding of reading materials. So, when they use this strategy, they can quickly get a new vocabulary that will be useful for them. And if they get a new vocabulary, their English skills will be improved. In the future, this has a positive impact on the students.

Richards and Renandya (2002) have noted the importance of vocabulary, suggesting that vocabulary plays a crucial role in the learning of a foreign language and in language skills that can influence how well learners speak, listen, read and write. Calderon et al. (2005) with English-language learners have shown that, in addition to teaching vocabulary before reading, their discourse on the text after reading leads to the development of students' vocabulary. This affected students in their enthusiasm and eagerness to learn vocabulary, as well as their ability to comprehend a text. Their background knowledge, associated with the new materials since they were used to them, often enhances their critical thinking skills. According to J. D. Salinger (2006), VSS helps students learn how to use meaning to decide what is meant by words. It also helps students to learn how to make choices relevant to the value of concepts.

What are the constraints of the students in the learning of technical vocabulary using Vocabulary Self-Collection Strategy?

The constraints that are experienced by students when using this strategy were the process of searching the meaning of the words and lots of time-consuming just as already explained in findings. When they were selecting for new words, most of them had problems in understanding the word in their native language, Indonesian, and when they had already translated the words that are unfamiliar for them, it made them confused about the meaning. But this was only the initial case because they won't experience obstacles like this when they 
are used to it. Students experience difficulties in reading English texts, inadequate awareness of vocabulary has been described as one of the main problems (Gunning, 2002). Harmon and Hedrick (2005) say that struggling readers learn vocabulary when teachers "promote independent learning by allowing students to study self-selecting words" (p. 275). Cain and Oakhill (2011) found that reading influences the improvement of vocabulary since the vocabulary skills of learners who do not read regularly are affected negatively.

To overcome the constraints of this activity, efforts are needed to improve the ability of students to acquire vocabulary, as well as the ability of students to learn English. The only effort that can be made is to enhance the quality of learning through the implementation of effective learning strategies. Learning techniques are correct if a strategy that focuses on students and the Vocabulary Self-collection Strategy is a suitable strategy for them. The research has a purpose that is to know the students' perceptions of learning technical vocabularies through Vocabulary Self-collection Strategy.

Briefly, the Vocabulary Self-Collection Strategy aims to draw students' attention and interest in learning English, to make students collected and gained new vocabulary, and to understand keywords in reading, and the ability to comprehend in reading a text. There have been several attempts in the building of the students' vocabulary list to make them interested and attract their attention. They have been provided with an appropriate source, which is a journal that related to their specialization in their vocational high school; Audio-Video Engineering.

Throughout the process of collecting the words, students had an individual involvement and engagement in word acquisition, they are expected to develop and acquire new vocabulary by reading the journal. By their involvement and demand in the world learning experience, the VSS allows students to play an active role in the collection of words, to continually active search for meaning on their own, and then to retain words for a longer period.

Each student was given the Vocabulary Self-Collection Strategy before the start of the learning process. On the chart, students put new collected words and other information obtained from a journal that was previously given and then fill it in the chart. They had to collect unfamiliar and important words and list them to the chart such as the reason for selecting the words, students' definition, and dictionary/corpus dictionary's definition. This activity encouraged the students to be more active and independent in collecting words.

Besides, from the perceptions of the students about learning technical vocabulary through Vocabulary Self-collection Strategy showed that there was significant information from using this strategy. The VSS was able to retrieve students' motivation in learning vocabulary and was encouraged and interested in learning words through the VSS. When they have finished doing this activity, students received many benefits from using the Vocabulary Self-collection Strategy (VSS). It caught their attention and made them curious, stimulates students, made them interested, and they can demonstrate the new vocabulary they have learned. More importantly, they can comprehend the text after they have got a new vocabulary.

In addition, the result of this research showed that it has positive and valuable impacts such as constructed the students to become active and independent learners, encouraged them in learning English, and increased their vocabulary list in understanding new words in learning technical vocabulary using VSS as same as previous research that also have positive results for students. Secondary school teachers reported that their students had no specialized or disciplinary vocabulary; as a result, they found it difficult to understand disciplinary textbooks and manuals in English (Widodo, 2015). 
In using this strategy, students got advantages that they can develop their learning skills, find the best way to recognize words from their readings, strengthen their vocabulary, and be consistent (Martin, 2002:88).

\section{CONCLUSION}

The research was about to know the perceptions of vocational students on learning technical vocabularies through Vocabulary Self-collection Strategy (VSS). From the research, the researcher received information about Vocabulary Self-Collection Strategy that facilitate in students' learning process and the constraints that the students have during learning technical vocabulary using this strategy. Learning vocabulary is one of the most frequently debated aspects of learning English as a foreign language as it is something different and new from the native language of a student, if a word is selected as an interesting and important word to know and to use, it can be translated into the native language of students who are studying English. Learning vocabulary can be difficult as many teachers do not have confidence in the best practice in vocabulary teaching and often do not know where to begin to develop the educational importance in word learning.

To meet this matter and target, the teacher should prepare and identify the appropriate strategy to be implemented in the teaching and learning process. The teaching of Vocabulary Self-collection Strategy (VSS) will be obtained satisfying results for both teachers and students. The strategy involved some acts, notably generating attention and interest among students, collecting and discovering key vocabulary contained in the text, establishing a connection between key vocabulary and text material, and comprehending the text as a whole. This strategy also supposed to learn in groups so the students can share their ideas and thinking with their friends, group activity makes the students more confident and enthusiastic.

Vocabulary Self-collection Strategy (VSS) chart is a media to define and collect the information and key vocabularies that can help them in comprehending the text that has already given to the students. This strategy not only helps students become more interested, actively, and independently in learning words, but also helps them increase their vocabulary list and improve their cognitive ability to learn words. The VSS leads to better comprehension and production words and influences the students' learning experience in English. In this section, the author(s) should give his/her comprise statement regarding the major findings and implications of the study, but not the whole study. It is not suggested to bring any new information in the conclusion.

\section{ACKNOWLEDGEMENT}

I would like to express my sincere gratitude to the participants and the school English teacher that engaged in this research project. My heartfelt thanks also go to Mr. Elih Sutisna Yanto, S.Pd., M.Pd. and Mr. Mobit, S.Pd., M.Pd. (Universitas Singaperbangsa Karawang) as my advisors who guided me until I finished making this research since preliminary draft. 


\section{REFERENCES}

Alqatani, M. (2015). The Importance of Vocabulary in Learning and How to be Taught. International Journal of Teaching and Education, 3, 21-34.

Amantina Pervizaj, Vehebi Sofiu, Bujar Kelmendi. (2016, August). Professional vocabulary learning strategies in content courses taught in English. International Journal of Scientific \& Engineering Research, 7(8), 395-439.

Asyiah, D. N. (2017). The Vocabulary Teaching and Vocabulary Learning: Perception, Strategies, and Influences on Students' Vocabulary Mastery. Jurnal Bahasa Lingua Scientia, 9, 293-318.

Bower, M. (2006). Virtual Classroom Pedagogy. Research Gate, 148-152.

Gedera, D. S. (2014). Students' experiences of learning in a virtual classroom. International Journal of Education and Development using Information and Communication Technology, 10, 93-101.

Haggard, M. R. (2015). The vocabulary self-collection strategy: Using student interest and world knowledge to enhance vocabulary growt. International Journal of Reading Association, 29, 634-642.

Hsu, W. (2014). Measuring the vocabulary load of engineering textbooks for EFL undergraduates. Elsevier System, 54-65.

Jennifer L. Schneider, Rachel Foot. (2012). Teaching Strategies to Support Vocational Education Students' Reading Literacy. The Clearing House: A Journal of Educational Strategies, Issues and Ideas, 32-36.

Khatib, F.M.M. \& Maarof, N. (2014). Self-efficacy perception of oral communication ability among English as a Second Language (ESL) Technical Student. Elsevier System, 98104.

Khodary, M. M. (2017). Using the Vocabulary Self-Collection Strategy Plus to Develop University EFL Students' Vocabulary Learning. English Language Teaching, 10, 135144.

Krich Rajprasit, Panadda Pratoomrat, Tuntiga Wang, Supanit Kulsiri \& Saengchan Hemchua. (2014). Use of the English language prior to and during employment: experiences and needs of Thai novice engineers. Global Journal of Engineering Education, 16, 27-33.

Krich Rajrasit, Saengchan Hemchua. (n.d.). The English Language \& Communication in the International Workplace: An Examination of Thai Computer Engineering Professionals. The Southeast Asian Journal of English Language Studies, 21, 109-124.

Muhamad Fauzi Rahman, Rendi Rinaldi, Iman Santoso. (2019). The Use of Vocabulary SelfCollection Strategy to Improve Students' Vocabulary Mastery. Professional Journal of English Education, 2, 93-99.

Natalie Kang, J.-A. N.-S. (2017). Teaching Vocabulary at the Upper Primary Levels with the Vocabulary Self-collection Strategy. Research Gate, 115-135.

$\mathrm{Ng}$ Yu Jin, Lee Yi Ling, Chong Seng Tong, Nurhanis Sahiddan, Alicia Philip, Noor Hafiza Nor Azmi, and Mohd Ariff Ahmad Tarmizi. (2013). Development of the Engineering Technology Word List for Vocational Schools in Malaysia. International Education Research, 43-59.

Ngah, E., Radzuan, N.R.M., Fauzi, W.J., \& Abidin, N.A.Z. (2011). The need for competent work ready English language learners. Elsevier System, 29, 1490-1499.

Poedjiastuti D,. \& Rifah, L. (2019). English Communication Needs of Engineering Student. International Journal of Language and Linguistics, 7, 69-77.

Qi Pan, Runjiang Xu. (2011). Vocabulary Teaching in English Language Teaching. Theory and Practice in Language Studies, 1, 1586-1589. 
R. T. Pithers \& Rosemary Lim. (2006). A non-english-speaking background in adult vocational education: breaking through the barrier. Journal of Vocational Education and Training, 49:4, 531-544.

Riemer, Marc J. (2002). English and Communication Skills for the Global Engineer. UNESCO International Centre for Engineering Education (UICEE), 6, 91-100.

Rini Fitria, Salwa. (2018). Students' Perceptions of English Oral Comunication Usage During Practice Learning Program. Inovish Journal, 3, 155-162.

Sarimah Shamsudin, Noraini Husin, Amerrudin Abd. Manan. (2012). Exploring fundamental engineering word list for engineering students: A literature review. Akdeniz Language Studies Conference 2012, 1275-1281.

Shivani Thakur, Shawaldeep Kaur, Pankaj Vikas Thakur, Deepali Rajat Nanda. (2013). English Teaching to Engineering Students difficulties and Solutions. Journal of Literature, Languages and Linguistics, Vol. 2, 55-59.

Supatra Wanpen, Kavintra Sonkoontod, Kittiporn Nonkhukhetkong. (2012). Technical Vocabulary Proficiencies and Vocabulary Learning Strategies of Engineering Students. Elsevier System, 312-320.

Takur, S. (2013). English Teaching to Engineering Students difficulties and solutions. Journal of Literature, Languages, and Linguistics, Vol. 2, 55-59.

Tatzla, D., \& Messnarza, B. (2013). Testing foreign language impact on engineering students' scientific problem-solving performance. European Journal of Engineering Education, $38,620-630$.

Teresa Mihwa Chung, Paul Nation. (2003). Technical vocabulary in specialised texts. Reading in a Foreign Language, 15, 103-116.

Teresa Mihwa Chung, Paul Nation. (2004). Identifying technical vocabulary. Elsevier System, 251-263.

Virginia Braun, Victoria Clarke. (2013). Successful Qualitative Research a practical guide for beginners. London: SAGE Book.

Yanto, E. S. (n.d.). Implementing Vocabulary Self-Collection Strategy in the EFL College Classroom in Engaging Students' Communicative Classroom. Journal of Teaching \& Learning English in Multicultural Contexts, 1, 14-22.

Yanto, E.S., \& Nugraha, S.I. (2018). Video viewing as a mediation of learning content-based vocabulary: Assisting students in understanding disciplinary vocabulary in context. Indonesian Journal of Applied Linguistics, 8, 316-324. 